TABLE Clinical features in 45 reported cases of inv dup (15).

\begin{tabular}{ll}
\hline & $\%$ \\
\hline Mental retardation & 98 \\
Developmental delay & 87 \\
Abnormal tone & 58 \\
Seizures & 53 \\
Abnormal ears & 51 \\
Strabismus & 49 \\
Growth retardation & 42 \\
Behaviour disturbance & 37 \\
Abnormal dermatoglyphs & 33 \\
Antimongoloid slant & 31 \\
High arched palate & 29 \\
Abnormal speech & 29 \\
Epicanthus & 20 \\
Abnormal EEG & 11 \\
Facial asymmetry & 7 \\
Anteverted nares & 5 \\
Kyphoscoliosis & 5 \\
\hline
\end{tabular}

mosaic, and in the remainder parental karyotypes were not performed. In the non-inherited group, parental ages were stated in 20 families: for these the average maternal age at birth was 33.4 years and the average paternal age was 37.4 years. All of these de novo cases have been isolated events. The recurrence risk for parents with normal chromosomes thus appears to be low. To date there have been three reports of recurrence, two owing to parental translocation and one to maternal mosaicism. Those cases where a parental translocation was the cause had additional phenotypic features reflecting the partial trisomy or monosomy of the other chromosome involved in the translocation. In these situations amniocentesis is indicated for future pregnancies. $^{2} 8$

The origin of the extra chromosome in the noninherited cases is unknown. Various theories have been postulated. ${ }^{11} \mathrm{~A}$ study of the relative significance of birth order to maternal age and paternal age might help to clarify the likely parental origin in view of the observed increase in mean parental ages.

We wish to thank Action Research for the Crippled Child for their continued support.

References

1 Parker CE, Alfi OS. Partial trisomy of chromosome 15. Lancet $1972 ; \mathrm{i}: 1073$.

2 Wisniewski L, Hassold T, Heffelfinger J, Higgins JV. Cytogenetic and clinical studies in five cases of inv dup (15). Hum Genet 1979;50:259-70.

3 Mankinen CB, Holt JG, Sears JW. Partial trisomy 15 in a young girl. Clin Genet 1976;10:27-32.

4 Taysi K, Devivo DC, Sekhon GS. Partial trisomy 15 and intractable seizures. Acta Paediatr Scand 1979;68:445-7.

5 Bannister DL, Engel E. A G-like trisomy with a major 15 proximal supernumerary component derived from a D/E balanced maternal translocation. J Pediatr 1975;86: 916-8.

6 Howard PN, Stoddard GR, Yarbrough KM. Partial trisomy D and Giemsa banding. Am J Hum Genet 1974; 26:41 A.

7 Furbetta M, Rosi G, Biagioni M, Cossu P, Cao A. A case of extra small acrocentric bisatellited chromosome in a non-mongoloid child. Humangenetik 1975;30:259-63.

8 Breg WR. In: Yunis JJ, ed. New chromosomal syndromes. New York: Academic Press, 1977:322.

9 Zannoti M, Preto A, Giovanardi PR, Dallapicolla B. Extra dicentric pter leads to q21/22 chromosomes in five unrelated patients with a distinct syndrome of progressive psychomotor retardation, seizures, hyper reactivity and dermatoglyphic abnormalities. J Ment Defic Res 1980; $4: 235-42$.

10 Fujita H, Sakamoto Y, Hamamoto Y. An extra idic (15p) (q11) chromosome in Prader-Willi syndrome. Hum Genet 1980;55:409-11.

11 Schreck RR, Breg WR, Erlanger BF, Miller OJ. Preferential derivation of abnormal human G-like chromosomes from chromosome 15. Hum Genet 1977;36:1-12.

Correspondence and requests for reprints to $\mathrm{Dr}$ J M Connor, Department of Medical Genetics, Duncan Guthrie Institute of Medical Genetics, Yorkhill, Glasgow G3 8SJ.

\title{
Interstitial deletion of the short arm of chromosome 4
}

\author{
M RAY, J EVANS, C ROCKMAN-GREENBERG, AND D WICKSTROM \\ Division of Human Genetics, and Department of Pediatrics and Child Health, University of Manitoba \\ and Health Sciences Centre, Winnipeg, Manitoba, Canada.
}

SUMMARY A 17 year old girl investigated for mental retardation and minor anomalies was found to have an interstitial deletion of $4 \mathrm{p}$. Her clinical and cytogenetic findings are compared with previous reported case of interstitial $4 p$ deletion and with terminal $4 \mathrm{p}-$ deletions (WolfHirschhorn syndrome).

Received for publication 5 September 1983. Accepted for publication 3 October 1983.
Before chromosome banding it was not possible to distinguish terminal and interstitial deletions and therefore few interstitial deletions have been reported. We describe a 17 year old girl with an interstitial deletion of segment p12p15 of chromosome 4. Francke et $a l^{1}$ reported a similar patient with a deletion of segment $4 \mathrm{p} 11 \mathrm{p} 15$. These patients show some similarity in clinical features suggesting that a recognisable phenotype may be associated with this deletion. 


\section{Case report}

The patient was born on 3.7.62, the second child of Cree Indian parents. Birth weight was $2721 \mathrm{~g}$. Early medical records are incomplete but she was apparently a very placid child who was healthy, apart from episodes of atelectasis at the age of 2 years and pneumonia at the age of 4 years. Motor and language development were significantly delayed and she walked independently at 6 years and used single words at 3 years. A clinical diagnosis of Down's syndrome was apparently considered. Because of parental neglect and the unavailability of appropriate schooling she was fostered in Winnipeg at 11 years of age and formally investigated for mental retardation. She was found to be functioning at a 3 to 5 year level. A complete physical examination was not carried out but she was noted to be microcephalic and to have a convergent strabismus. A right convex scoliosis was noted at 13 years. Her health was otherwise good except for fractures of the left humerus and left radius sustained in falls. When she was seen for a routine examination at 17 years the diagnosis of Down's syndrome was questioned and she was referred to the department of genetics for evaluation.

Further history revealed that the mother had six other apparently normal children and had been treated for mitral prolapse after the proband's birth. The father had been treated for hypothyroidism. Physical examination revealed a co-operative Indian girl (fig 1) with height and weight on the 40th centile for age, OFC $53.5 \mathrm{~cm}$ (25th centile); brachycephaly; a poorly formed right parietal whorl; low anterior hairline; medial eyebrow flaring; straight eyelashes; slightly upward slanting palpebral fissures; prominent epicanthic folds; supraorbital puffiness; normal inner and outer canthal distances $(8.8 \mathrm{~cm}$ and $3.6 \mathrm{~cm}$ respectively); relatively small eyes (palpebral fissures $2.6 \mathrm{~cm}$ ); strabismus; large nose; normal palate; broad alveolar ridges; spade shaped incisors with fused left lower incisors; flattened malar area; prominen premaxilla; large mouth $(5.7 \mathrm{~cm})$; thick lips; milक् facial asymmetry with the left side flatter; ears normal in position and rotation but cupped witks prominent antihelices; helices notched bilaterall $\$$ and thinned in the middle third; neck of normat length with no webbing and circumference $31.7 \mathrm{~cm} ;$ slight cubitus valgus with some laxity of the elbows; midfinger to total hand ratio of $40.5 \%(<3$ rd cen $\vec{\omega}$ tile); broad palms $(9 \cdot 2 \mathrm{~cm})$; restricted metacarpo. phalangeal and proximal interphalangeal joints causing camptodactyly of the 2nd to 5th digits bilaterally; slight skin syndactyly more pronounced between digits 2 and 3 ; subluxating slightly webbed $\dot{w}$ thumbs; mild distal hypoplasia of the digits with short nails and rounded fingertips (fig 1); simple arches on all digits, except the third fingers bilaterally which have low ridge count ulnar loops $\overrightarrow{\dot{x}_{\vec{c}}}$ proximal axial triradii bilaterally with a thenar loop and additional distal triradius on the left; normal ${ }^{\mathbb{D}}$ palmar creases; $\mathrm{I}^{3}$ loop on left, $\mathrm{I}^{4}$ loop on right $; \overrightarrow{\mathrm{c}}$ missing right $C$ triradius; prominent heels; pes+ planus; hallucal patterns of distal loops; normalo chest and abdomen with an accessory nipple on the left; normal female genitalia, Tanner stage III sexual development; a café-au-lait spot on the righto breast; some hypo- and hyperpigmented spots on $\frac{\mathrm{Q}}{\mathrm{O}}$ the cheeks; small 'cigarette paper' scars on the left leg and neck; normal muscle development buto를 increased tone; brisk and symmetrical reflexes; flat ${ }^{3}$ footed gait. Her developmental level was approximately 11 to 12 years but this was not formally? assessed. A venous blood sample was obtained for cytogenetic analysis.

\section{CYTOGENETIC ST UDIES}

Cytogenetic analysis on peripheral lymphocytes using $Q$ banding revealed a deletion of the short arm of one chromosome 4. The exact position of 5 the deletion, terminal or interstitial, could not be

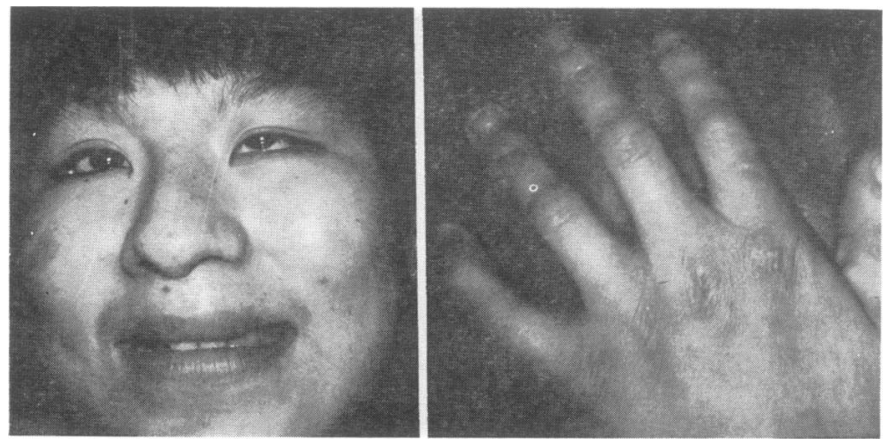

FIG 1 The patient aged 17 years with camptodactyly of the left hand. 

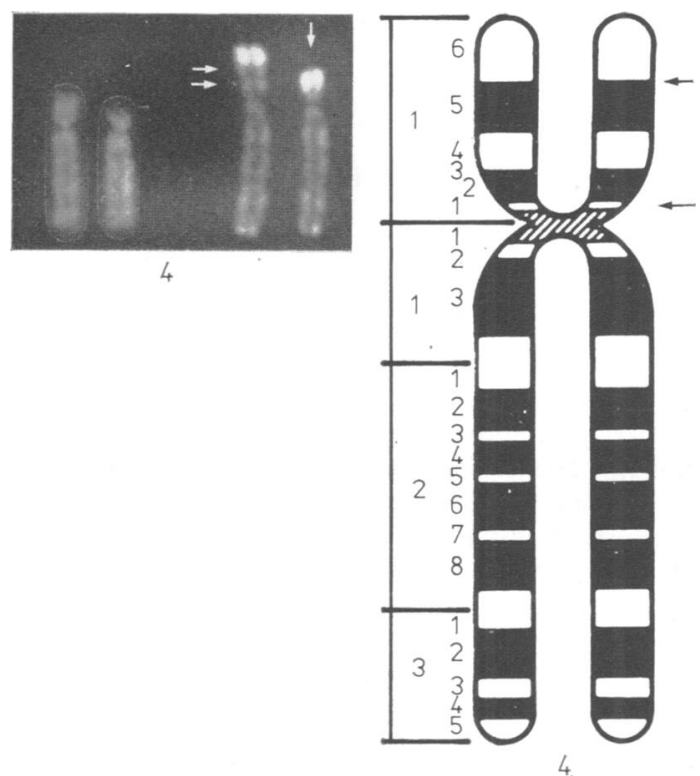

FIG 2 Partial karyotype showing $\operatorname{del}(4)(p 12 p 15)$ : $Q F Q$ banding (left), $R B A$ banding (middle), and diagrammatic representation of chromosome 4 (right). Arrows indicate where breakages occurred.

determined owing to the nature of $\mathrm{Q}$ bands in this region (fig 2). $R$ banding analysis of a second blood sample, using BudR-AO, showed an interstitial deletion with breakpoints at p12 and p15 (fig 2). There was no evidence for insertion of the missing piece into another chromosome. No mosaicism was found in 50 cells analysed. The karyotype was thus designated 46,XX,del(4)(p12p15). Chromosomal analysis of both parents revealed normal karyotypes. This suggests that the interstitial deletion arose during gametogenesis in one of the parents or immediately after fertilisation.

\section{Discussion}

Now that banding of high quality can be achieved, interstitial deletions with accurate breakpoints are being recognised more frequently. We are unaware of other published cases involving an interstitial deletion of the segment $4 \mathrm{p} 12 \mathrm{p} 15$ except the girl reported by Francke et $a l^{1}$ whose deletion involved approximately the same segment (p11p15). We do know of one other potential case with an interstitial deletion of $4 \mathrm{p}$ who closely resembles our patient facially (M Preus, 1982, personal communication).
Phenotypically, our patient does not resemble those with Wolf-Hirschhorn syndrome but has findings in common with the patient of Francke $e t$ al. ${ }^{1}$ In particular, both had relatively small eyes, large noses, cubitus valgus, broad hands, a high number of digital arches, and short fingers. Photographs of the two suggest a similar overall facial appearance.

The classic $4 p-$ syndrome has distinct clinical features including growth deficiency, hypertelorism, downward slanting palpebral fissures, colobomata, cleft lip, digital thumbs, seizures, and profound mental retardation. In most cases the abnormal short arm is nearly half the normal length. Lejeune et $a l^{2}$ and Perez-Castillo and Abrisqueta ${ }^{3}$ have shown that typical Wolf-Hirschhorn syndrome occurs only if band 4 p16 is lost. It is also known that duplications or deletions of comparatively small regions of chromosome 21 or $5 p$ are responsible for the phenotypic features of Down's and cri-du-chat syndromes respectively. ${ }^{45}$

We agree with Francke et $a l^{1}$ that a 'proximal $4 p$ - syndrome' exists that involves the segment $4 \mathrm{p} 11 \rightarrow \mathrm{p} 15$ and which is distinguishable clinically and cytologically from the 'distal $4 \mathrm{p}$ - syndrome' involving deletion of $4 \mathrm{p} 16$. Advanced banding techniques need to be used to distinguish precisely such structural chromosomal abnormalities. Detailed knowledge of the phenotype and prognosis associated with specific chromosomal anomalies is necessary for proper interpretation of abnormal cytogenetic findings and for genetic counselling, especially in antenatal cytogenetic diagnosis.

\section{References}

1 Francke U, Arias DE, Nyham WL. Proximal 4pdeletion: phenotype differs from classical $4 p$ - syndrome. J Pediatr 1977;90:250-2.

2 Lejeune J, Rethoré MO, Dutrillaux B, Lafourcade J, Cruveiller J, Drillon P. Syndrome $4 \mathrm{p}$ - par translocation paternelle $\mathrm{t}(4 ; 20)(\mathrm{p} 15 ; \mathrm{p} 12)$. Lyon Med 1975;233:271-4.

3 Perez-Castillo A, Abrisqueta JA. Ring chromosome 4 and Wolf syndrome. Hum Genet 1977;37:87-91.

4 Williams JD, Summitt RL, Martens PR, Kimbrell RA. Familial Down syndrome due to a t $(10 ; 21)$ translocation; evidence that the Down phenotype is related to trisomy of a specific segment of chromosome 21 . Am J Hum Genet 1975;27:478-85.

5 Niebuhr E. Cytogenetic observations in 35 individuals with a 5 p - karyotype. Hum Genet $1978 ; 42$ :143-6.

Correspondence and requests for reprints to Dr M Ray, FE 028, Community Services Building, Health Sciences Centre, 700 William Avenue, Winnipeg, Manitoba, Canada R3E 0Z3. 